\title{
O ADOLESCER E SER MÃE: REPRESENTAÇÕES SOCIAIS DE PUÉRPERAS ADOLESCENTES
}

Dafne Paiva Rodrigues ${ }^{1}$, Francisco Rafael de Araújo Rodrigues², Lucilane Maria Sales da Silva ${ }^{3}$, Maria Salete Bessa Jorge $^{4}$, Léa Dias Gomes Pimentel Vasconcelos ${ }^{5}$

RESUMO: Objetivou-se apreender as representações sociais de puérperas adolescentes sobre ser mãe na adolescência. Trata de estudo fundamentado na Teoria das Representações Sociais de Moscovici, desenvolvido em um hospitalmaternidade público do município de Fortaleza-CE com 25 puérperas adolescentes através de entrevista semiestruturada. A construção das representações sociais sobre a maternidade na adolescência revela a edificação de opiniões contraditórias. As contradições mais visíveis foram: ser mãe e ser mãe na adolescência, em que a primeira passa a ser concebida como uma virtude, enquanto a segunda estereotipada como prisão através das dificuldades enfrentadas no desenvolvimento do papel. Conclui-se que a maternidade na adolescência revela a importância de programas educativos sobre a saúde sexual, com enfoque na intersetorialidade entre as escolas, os serviços de saúde e a sociedade para desenvolver mecanismos que identifiquem e intervenham junto às adolescentes com alto risco para a maternidade precoce.

PALAVRAS-CHAVE: Identificação social; Mães; Adolescente; Período pós-parto.

\section{BECOMING ADOLESCENT AND BEING MOTHER: SOCIAL REPRESENTATIONS OF ADOLESCENTS IN THE POST PARTUM}

ABSTRACT: The objective was to apprehend the social representations of adolescents in the post partum period about being a mother in adolescence. This study was based on the Theory of Social Representation of Moscovici, and was developed in a public maternity hospital in the municipality of Fortaleza-CE with 25 adolescents in the post partum period, through semi-structured interviews. The construction of social representations about motherhood in adolescence shows contradictory opinions. The most visible contradictions are: being a mother and being a mother in adolescence, in which the first shall be designed as a virtue, while the second is stereotyped as prison, through the difficulties faced in developing the motherhood role. The conclusion is that the maternity in adolescence shows the importance of educational programs on sexual health, focusing on the intersectoriality between schools, health services and society to develop mechanisms to identify and intervene with the teenagers at high risk for early motherhood .

KEYWORDS: Social identification; Mothers; Adolescent; Postpartum period.

\section{ENTRAR EN LAADOLESCENCIA Y SER MADRE: REPRESENTACIONES SOCIALES DE PARTURIENTAS ADOLESCENTES}

RESUMEN: Se objetivó aprehender las representaciones sociales de parturientas adolescentes sobre ser madre en la adolescencia. Se trata de un estudio fundamentado en la Teoría de las Representaciones Sociales de Moscovici, desarrollado en un hospital-maternidad público del municipio de Fortaleza-CE con 25 parturientas adolescentes a través de entrevista semiestructurada. La construcción de las representaciones sociales sobre la maternidad en la adolescencia revela la edificación de opiniones contradictorias. Las contradicciones más visibles fueron: ser madre y ser madre en la adolescencia, en que la primera pasa a ser concebida como una virtud, mientras que la segunda estereotipada como prisión a través de las dificultades enfrentadas en el desarrollo del rol. Se concluye que la maternidad en la adolescencia revela la importancia de programas educativos sobre la salud sexual, con enfoque en la intersectorialidad entre las escuelas, los servicios de salud y la sociedad para desarrollar mecanismos que identifiquen e intervengan junto a las adolescentes con alto riesgo de maternidad precoz.

PALABRAS CLAVE: Identificación sociale; Madres; Adolescente; Período de posparto.

\footnotetext{
${ }^{1}$ Doutora em Enfermagem. Professora Adjunta do Curso de Graduação em Enfermagem da Universidade Estadual do Ceará-UECE. Coordenadora do Grupo de Pesquisa "Saúde da Mulher e Família”.

${ }^{2}$ Enfermeiro pela UECE. Membro do Grupo de Pesquisa Saúde da Mulher e Família-UECE.

${ }^{3}$ Doutora em Enfermagem. Professora Adjunta do Curso de Graduação em Enfermagem da UECE. Membro do Grupo de Pesquisa "Saúde da Mulher e Família”.

${ }^{4}$ Doutora em Enfermagem. Professora Titular do Curso de Enfermagem da UECE. Vice-coordenadora do Curso de Mestrado Acadêmico em Saúde Pública da UECE. Líder do Grupo de Pesquisa Saúde Mental, Família, Práticas de Saúde e Enfermagem.

${ }^{5}$ Enfermeira Obstétrica. Aluna do Curso de Mestrado Acadêmico em Cuidados Clínicos em Saúde da UECE. Membro do Grupo de Pesquisa "Saúde da Mulher e Família”.
}

Autor correspondente:

Dafne Paiva Rodrigues

Rua Paurilo Barroso, 63 - 60712-110 - Maraponga-CE

Recebido: 18/11/08

E-mail: dafneprodrigues@yahoo.com.br

Aprovado: 20/07/09 


\section{INTRODUÇÃO}

O processo de adolescer é um estado de transição dinâmico e importante para o crescimento e desenvolvimento do ser. O termo adolescência vem do latino adolescere, que significa crescer até a maturidade. Usa-se esse termo para designar o período de mudanças que vai dos 10 anos até a maturidade ${ }^{(1)}$.

A Organização Mundial de Saúde define a adolescência como o período da vida a partir do qual surgem as características sexuais secundárias e se desenvolvem processos psicológicos e padrões de identificação que evoluem da fase infantil para a adulta, entre eles a transição de um estado de dependência para outro de relativa autonomia, prolongando-se dos 10 aos 20 anos incompletos segundo seus critérios ${ }^{(2)}$.

Os censos demográficos e as contagens populacionais para os anos intercensitários mostram através de estimativas preliminares que em 2007 o Brasil já contava com mais de 39 milhões de jovens na faixa etária de 10 a 19 anos $^{(3)}$. Esse aumento da população, ocorrido nas últimas décadas, é resultado da transformação na estrutura etária da população brasileira, em função da queda da fecundidade, do declínio da mortalidade infantil e do aumento da esperança de vida.

A adolescência, por exemplo, constitui uma etapa do desenvolvimento humano caracterizado por modificações biológicas, psicológicas e sócio-culturais. $\mathrm{O}$ indivíduo que se encontra nesta fase peculiar de transição biopsicosocial apresenta transformações biológicas, em busca de uma definição de seu papel social, determinado pelos padrões culturais de seu meio $^{(4)}$. É um momento que se distingue pelas primeiras reações emocionais e transformações corporais próprias da puberdade, no qual o indivíduo enfrenta a perda dos caracteres biológicos infantis e a perda dos pais quanto à dependência infantil ${ }^{(5)}$.

A adolescência inicial é a época em que há mudanças significativas em quase todos os aspectos funcionais da criança na qual o adolescente de 12 ou 13 anos está assimilando uma enorme quantidade de experiências físicas, sociais e intelectuais novas. Já a adolescência final é a época da consolidação, na qual o jovem de 16, 17 ou 18 anos estabelece nova identidade, tendo objetivos e compromisso com papel mais claro. Sugere-se que a adolescência inicial seja uma época dominada pela assimilação, enquanto a fase final talvez seja um momento de acomodação ${ }^{(6)}$.
A gravidez na adolescência é uma ocorrência de maior destaque relacionado à sexualidade da adolescência e, na história da humanidade, não constitui um fenômeno recente, mas se evidencia desde a antiguidade, quando os contratos de casamento eram feitos com as meninas com a idade de 13 a 14 anos. De acordo com alguns autores a gravidez na adolescência, que era antes problemática exclusivamente familiar, resolvida muitas vezes por casamento às pressas ou por auxílio temporário em locais distantes, passou a ameaçar o futuro dessas jovens. Atualmente, gravidez no extremo inferior da vida reprodutiva tem sido objeto de preocupação, pois a gestação assim como o parto e a maternidade são problemas peculiares que, ao ocorrerem nessa fase da vida, trazem múltiplas consequências tanto à saúde física quanto aos aspectos emocionais e econômicos, repercutindo sobre a mãe adolescente e seu filho ${ }^{(7)}$.

As últimas décadas evidenciam dados alarmantes sobre o comportamento dos adolescentes no tocante à precocidade das relações sexuais de ambos os sexos. O número médio de filhos de mulheres adultas vem diminuindo no Brasil, enquanto a taxa de fecundidade entre adolescentes está em crescimento constante. Entre 1994 e 2004, a proporção de mães adolescentes cresceu de 18,4\% para 23,9\% no Nordeste. Para o Estado do Ceará, aproximadamente 24\% dos partos feitos pelo Sistema Único de SaúdeSUS, ocorridos em 1999, foram de mulheres com menos de 20 anos de idade ${ }^{(8)}$.

Apreender o pensamento de adolescentes sobre os sentidos de ser mãe é adentrar em suas singularidades, no universo das representações que transparece a realidade experienciada em função dessa condição. Para compreender esse processo de construção no senso comum das representações é necessário tornar-se sensível à individualidade, à coletividade, aos processos simbólicos e às vivências expressas no pensar, agir e sentir do cotidiano das adolescentes. A partir deste contexto, objetivou-se nesta pesquisa apreender as representações sociais de puérperas adolescentes sobre ser mãe na adolescência.

\section{REFERENCIAL TEÓRICO-METODOLÓGICO}

Esta pesquisa é um estudo de abordagem qualitativa e norteada pelos pressupostos teóricos e metodológicos das Representações Sociais ${ }^{(9-10)}$, que reconhecem o conhecimento no senso comum, e busca 
questões relativas ao sujeito, considerando a sociedade em que o mesmo se insere e sua história. A escolha ocorreu em virtude dela nos trazer à luz o conhecimento produzido no cotidiano dos sujeitos sociais da pesquisa, permitindo adentrar nos seus universos imaginários e simbólicos.

O estudo foi desenvolvido em um hospitalmaternidade público de atenção secundária de saúde, localizado no município de Fortaleza-CE, inserido na Secretaria Executiva Regional-SER VI. O Hospital em questão oferece atendimentos de urgência em ginecologia e obstetrícia, clínica médica (feminina), neonatologia e pediatria, além de consultas ambulatoriais e cirurgias eletivas em ginecologia, obstetrícia e mastologia. A unidade realiza ainda exames laboratoriais simples e especializados como raios $\mathrm{X}$, mamografia e ultra-sonografias.

A pesquisa teve como apoio o "Curso da Gestante” que é promovido pela enfermeira obstétrica e que reúne um grande número de adolescentes grávidas em acompanhamento pré-natal no ambulatório da instituição. O curso divide-se em dois módulos, sendo o primeiro destinado às gestantes que se situam no primeiro trimestre e o segundo para as gestantes que se encontram no segundo e terceiro trimestre de gestação.

A seleção dessa Instituição para a realização da pesquisa residiu no fato de estar colocada como a segunda maternidade em maior número de atendimentos do Estado do Ceará, localizada em uma região populosa e com um elevado índice de adolescentes grávidas. Além do fato de ser um hospital-escola em parceria com a Universidade Estadual do Ceará, facilitando os trâmites legais para realização da pesquisa.

Participaram do estudo 25 puérperas adolescentes na faixa etária de 10 aos 20 anos incompletos, conforme os critérios de classificação da Organização Mundial da Saúde-OMS ${ }^{(2)}$, determinadas durante o processo de amostragem teórica, isto é, quando as experiências foram se repetindo e respondendo ao objetivo da pesquisa em suas múltiplas dimensões. A coleta dos dados ocorreu de janeiro a abril de 2007 através de entrevista semiestruturada, aplicada individualmente e gravada em fita cassete mediante permissão concedida pelas participantes.

Os conteúdos que emergiram através das entrevistas foram submetidos à análise de conteúdo ${ }^{(11)}$. Esta forma de análise possibilitou a compreensão crítica dos conteúdos, buscando significar os sentidos manifestos além do que foi comunicado. Nesse tipo de análise, estudiosos ${ }^{(12-13)}$ destacam as significações explícitas ou ocultas presentes na organização dos processos mentais dos sujeitos por meio das produções discursivas.

Para realizar a análise de conteúdo foram seguidas as seguintes etapas operacionais ${ }^{(11)}$ : Na préanálise, as entrevistas foram transcritas na integra após a leitura das gravações, garantindo o máximo de fidedignidade às verbalizações coletadas. Assim, os discursos que surgiram foram fixados em textos, o que serviu para descrevê-los e interpretá-los com o intuito de compreender os significados conhecidos pelas participantes; a análise iniciou com a reunião de todas as entrevistas para a constituição do corpus e feitas leituras flutuantes. Em seguida, foram realizadas leituras detalhadas e orientadas pelos objetivos para compreensão mais detalhada e aprofundamento dos significados dos conteúdos. Após identificados os fragmentos das descrições que expressassem o fenômeno, foi estabelecida a decomposição do corpus e agrupamento do material em subcategorias e categorias. Estas foram validadas para comporem unidades de análise. As categorias que surgiram foram descritas e interpretadas por inferências com a literatura pesquisada embasada na Teoria da Representação Social.

Efetivou-se o estudo definitivo concomitante as concessões de informações quanto aos procedimentos que fizeram parte da pesquisa e consentimento livre e esclarecido das adolescentes e/ou seus responsáveis. Foi garantido também o anonimato dos sujeitos do estudo, tendo suas identidades substituídas por códigos como E-1..., E-25. Esta pesquisa apresentou parecer favorável a sua execução pelo Comitê de Ética em Pesquisa da Universidade Estadual do Ceará, com o n. de protocolo 05464338.

\section{RESULTADOS E DISCUSSÃO}

A partir da análise dos conteúdos apreendidos por meio dos recortes das unidades temáticas das entrevistas, foram construídos dois núcleos temáticos e oito categorias: O adolescer e a gravidez na adolescência com as categorias sentimentos ambivalentes, mudanças no estilo de vida, conceitos e ressignificações; e o outro núcleo temático: O adolescer e ser mãe na adolescência constituída pelas categorias significados, sentimentos, dificuldades e alterações físico-orgânicas. 


\section{O adolescer e a gravidez na adolescência}

O texto construído reúne as aproximações e distanciamentos qualitativos rodeados por um campo simbólico elaborado socialmente. Assim, observamos na Figura 1 as representações sociais das puérperas adolescentes sobre a gravidez na adolescência, dando sentido a uma trama de significações através de seus núcleos temáticos.

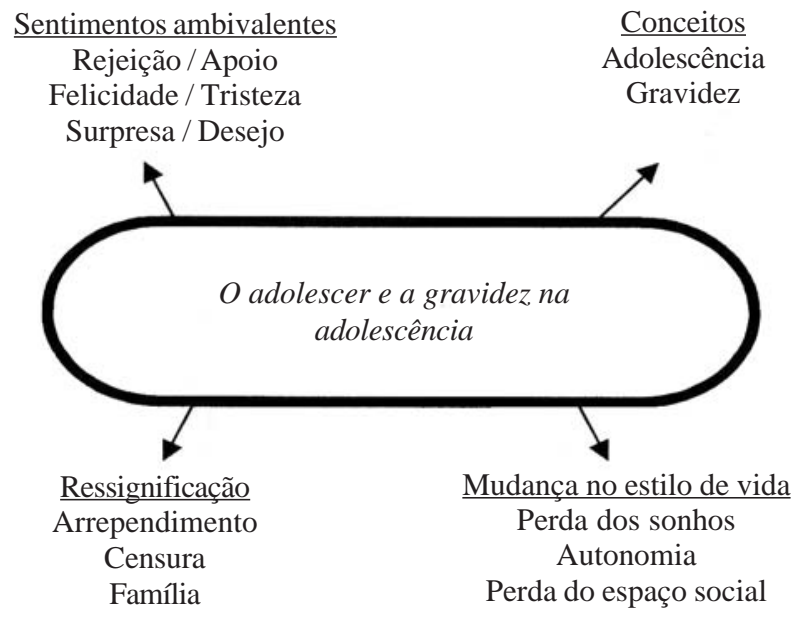

Figura 1 - Representações sociais das puérperas adolescentes sobre a gravidez na adolescência. Fortaleza-CE, 2007

O grupo das adolescentes entrevistadas apresenta nos discursos a construção de conceitos socialmente produzidos sobre a adolescência e a gravidez:

[..] foi bom, um tempo bom [Por quê?]. Eu me diverti né, tive tempo, assim, saía prás festas com meus amigos, era assim. Só isso mesmo. Foi assim, bom né, teve uma parte que eu me diverti, depois eu me casei, tive minha filha com 17 anos (E.10).

Eu tinha medo, prá mim eu ia morrer, aí fui embora pro interior e fiquei lá. Aí eu escondi minha gravidez durante sete meses. Foi. Minha mãe, ela suspeitava, mas ela não chegava prá mim e dizia né: você tá grávida. Venha aqui prá conversar comigo. Ela me chamava prá conversar né sendo que eu tinha vergonha. Toda vida quando ela me chamava eu saía, fugia, cortava o assunto. Aí escondi durante sete meses minha gravidez. Quando a barriga aumentou não consegui mais esconder, foi quando ela descobriu foi um choque prá ela né (E.1).

O conceito de adolescência ficou ancorado numa dimensão sócio-relacional e afetiva demonstrado por uma atmosfera positiva das novas situações vividas. Assim, a adolescência foi metaforizada como um período da vida para a formação dos grupos de amigos, liberdade para namorar, busca de novos espaços sociais, possibilidade de fazer compras só para ela, alegria e diversão.

O conceito de gravidez ficou ancorado na dimensão fisiológica e psicológica. As adolescentes estabelecem uma relação direta com as alterações no corpo, estereotipando a gravidez pela presença da barriga que vai crescendo e revelando-a como um momento inicialmente de negação e, posteriormente, de ansiedade devido à dinâmica do parto e preocupação com o bem-estar do filho que estava em gestação.

A gravidez, apesar de não conseguir se dissociar e constituir um evento de aspecto biológico, é especial na vida da mulher, desenvolve-se dentro de um contexto social e cultural que influencia e determina a evolução da gravidez bem como a sua assistência. O ciclo grávido-puerperal acarreta grandes modificações não apenas corporais, como na maneira de ser da mulher e em suas relações pessoais, constituindo-se em período de transição existencial ${ }^{(14)}$.

Identificou-se nesse estudo que o caminho percorrido durante a gravidez ancora-se nas seguintes ressignificações:

Eu era prá ter pensado antes, em tudo na minha vida que perdi quando engravidei. Tanto faz ela tá como não tá, é uma coisa que vai ser prá mim o resto da minha vida. Não é uma coisa que eu vou fazer, encostar e deixar ali. Prá onde for prá onde eu ir tem que levar e já que eu quis né, não vou abandonar. Muitos meios da gente prevenir têm, a gente previne se quiser se não quiser e eu errei em não se prevenir. Eu penso assim, já que você não quer, então não vá atrás. Minha cabeça é essa, procurou, agora é responsabilidade até o resto da vida (E.25).

Contraditoriamente, esse momento é recoberto de arrependimento no tocante à gravidez e enfatizado quando toma consciência da eternidade da função de mãe e necessidade de abdicar de atitudes por ela tão cobiçadas.

Tudo sou eu, sempre sou eu. E logo que o pai dele também não assumiu né. Meu primeiro menino. Aí quando eu engravidei e contei prá ele, ele disse que o filho não era dele. Hoje em dia eu sou feliz como 
mãe. Mas na gravidez mesmo foi muito difícil, sofri demais. Mas hoje em dia eu estou muito feliz, eu amo muito ela, ela é muito importante prá mim (E.1).

O sofrimento sentido pela ausência do companheiro durante a gravidez e na composição familiar, ressignifica o conceito tradicional de família. A reelaboração desse conceito traduz a necessidade da jovem se auto-afirmar como grávida e assumir responsabilidades de mãe sozinha. As entrevistas também revelam que a representação social da gravidez na adolescência ficou ancorada na esfera dos sentimentos, em que as sensações de ser mãe deixam transparecer certa ambivalência entre a fantasia das participantes e a condição de realidade em que se encontravam.

Para algumas entrevistadas, a gravidez na adolescência é objetivada inicialmente como uma surpresa, como algo inesperado, causando um impacto em sua vida:

Ficava só chorando quando descobri, por que assim, como eu te falei, eu não imaginava ser mãe. É assim, eu não sabia assumir. Agora de segunda eu já tava acostumada (E.12).

Foi bom, foi por que eu quis né. Prá mim foi bom. É por que era tudo o que eu queria né, um filho. Que nem toda mulher quer. Faz é tempo que eu tava tentando, como eu já disse né. Ia fazer dois anos. Prá mim foi ótimo. Aqui vai ser minha companhia (E.5).

Contraditoriamente, outras revelam a consciência de suas atitudes e do desejo, mesmo que inconsiderado, de ter um filho, concretizado através da confirmação da gravidez. Esse desejo de engravidar está metaforizado como a realização de um sonho. A sensação prazerosa sentida com a descoberta da gravidez se encontra elaborada na ideia de um projeto fantasioso, de um desejo sempre sonhado, mas que deveria ser concretizado quando planejado. $\mathrm{O}$ fato de existirem adolescentes que desejam engravidar poderia ser justificado pela percepção, por parte das jovens, da falta de estrutura para constituir uma nova família naquele momento ${ }^{(15)}$.

Primeiro de tudo eu não tive apoio de ninguém, aliás, tudo que eu fazia a minha mãe dizia que a culpada era eu né, que eu não tinha cabeça prá pensar, por que eu acho que já que aconteceu nossa família tem que apoiar né. Só que quando eu engravidei todo mundo virou as costas sabe ninguém nem queria saber né. Por que dizia que era eu que queria né, foi falta de cuidado meu (E.10).

Ah! Foi quando eu engravidei, meu marido disse que teve abuso de mim, aí arrumou outra, aí eu sofri nesse tempo. Foi o conflito maior foi esse. Ah! Nesse momento eu tinha me arrependido de ter engravidado. Mas só que não podia fazer nada, não ia abortar, nem matar (E.4).

A descoberta da gravidez é marcada para as jovens pela significação da rejeição sobre a perda dos afetos, sendo objetivada na ausência e/ou medo de perda do companheiro e do distanciamento dos pais e irmãos. A falta de apoio do companheiro é referida pelo abandono e sentida através da solidão. O desamparo familiar é representado pela exclusão das adolescentes do grupo familiar. No âmbito familiar, a gravidez na adolescência parece indicar dificuldades nas relações entre pais e filhas e nas condições contextuais para o desenvolvimento psicológico da filha. No âmbito individual, a jovem gestante se questiona "por que isso aconteceu justamente comigo?" e “o que será agora de minha vida?”.

Em outras palavras, a gravidez na adolescência traz sérios problemas para programas de saúde pública, para projetos educacionais, para a vida familiar e para o desenvolvimento pessoal, social e profissional da jovem gestante ${ }^{(16)}$.

As adolescentes informam que o surgimento da gravidez é objetivado por momentos de tristeza, medos e incertezas devido à pressão social e familiar que é submetida, além dos conflitos internos pela interrupção do processo socialmente aceito de adolescer e pela antecipação da identidade adulta. Ao mesmo tempo, essa tristeza parece ser disfarçada pela racionalização dos afetos que se ocultam pela fachada do desejo de ter um filho, pela presença do companheiro e pelo apoio familiar. Com isso, a gravidez na adolescência passa a ser objetivada como um momento repleto de felicidade e satisfação.

Eu sempre quis ser mãe, mas eu não queria assim. Queria me casar ter meu marido, minha família. Então, foi difícil, difícil prá mim né. Mas, naquele momento eu fiquei meio perdida, não conseguia raciocinar direito. Era assim uma coisa que tinha 
acontecido, mas num sonho como se não fosse realidade né. Um sonho que eu tive, no outro dia era realidade. Mas, eu não caí na real entendeu (E.25).

Prá mim foi difícil sim por que eu tinha 17 anos, estudava, aí quando a minha mãe ficou sabendo também, foi aquela briga né, aí eu parei de estudar, depois quando o menino nasceu até hoje não continuei mais. Foi. Foi muito difícil. Não tava preparada né (E.13).

As falas das adolescentes entrevistadas descrevem as mudanças ocorridas no estilo de vida das jovens com a gravidez, na tentativa de se adaptar à nova condição. As expressões revelam a perda dos sonhos como algo marcante, objetivado no abandono dos estudos, dificuldade em trabalhar, em casar-se e poder formar uma família, e o ganho de novas atividades com base em cuidar do serviço doméstico, cuidar do filho e irem ao médico.

A gravidez foi ancorada também na diminuição da autonomia devido à perda dos espaços sociais próprios aos adolescentes, os quais ainda estavam em processo de construção e delimitação, para restrição ao ambiente doméstico. As verbalizações referem que as adolescentes sentem falta de estudar, sair com os amigos, comprar suas coisas próprias e se divertirem nas praças e festas.

\section{O adolescer e ser mãe na adolescência}

O texto construído reúne uma rede de significados psicossociais, cognitivos e biológicos, rodeados por um campo simbólico elaborado socialmente. As entrevistadas expressam em seus discursos manifestações sobre os sentidos de ser mãe na adolescência. Este é construído a partir da dinâmica das atribuições sociais que a jovem deve desempenhar com a maternidade.

Ser mãe é superação. Você deixa de ser adolescente e passa a ser adulto, você tem que superar, tem que ser adulto, você é responsável por outra vida. Que tenho prá mim cuidar, dar a comida, bebida, carinho, levar prá escola [...] dar uma vida boa é de responsabilidade toda minha (E.1).

Ser mãe é uma pessoa responsável que a gente adquire ser [...] é por que a gente quer mesmo. Assim, de cuidar, de zelar a criança, botar na escola, de ter carinho, ter um amigo assim, ser uma mãe pro que precisar (E.8).

O conceito construído de mãe adolescente é representado como um eu-ideal, responsável pelo cuidado do filho, boa educação, carinho, bons exemplos e dedicação. O papel social de mãe é percebido também pela sua infinitude, em que se refere como uma tarefa para o resto da vida.

As mães adolescentes oferecem sempre boas condições de cuidado à criança até mesmo se comparado às mães adultas. Existe uma considerável variabilidade nos padrões de interação das mães adolescentes com os seus filhos e como algumas mães adolescentes são capazes de interações mais adequadas, sendo exemplos de boas condutas ${ }^{(17)}$.

A maternidade ficou ancorada no domínio físicoorgânico, metaforizado pelas alterações anatômicas e fisiológicas que o corpo sofre após o nascimento de um filho. O conflito entre a autoimagem e o corpo idealizado pode ser acentuado quando se considera que, durante a gravidez, as transformações corporais ocorrem em um curto espaço de tempo, exigindo da gestante um processo de adaptação, o que certamente interfere na sua imagem corporal $^{(18)}$.

Por que eu me vejo no espelho hoje eu não vejo mais a [...] de antes entendeu, você muda, cria estria, cria varize, entendeu. Um pé inchado, uma coisa ou outra, tudo isso muda por que a pessoa que eu era antes eu já não é mãe, você, tudo que você pegar, você pode usar produto de beleza e pronto, e quando você é mãe o dinheiro que você pega já tem um determinado caminho, pro seu filho (E.4).

As distorções da autoimagem implicam na redução da autoestima da adolescente. Agora seu corpo apresenta-se modificado com o aumento de peso, marcas, estrias, varizes, barriga e seios aumentados estereotipando-as como mãe e afastando-as da valorização do corpo esbelto que justapõe a imagem da adolescente diante da sociedade. A transfiguração do corpo da jovem vem repleta de sentimento de medo pela rejeição social. As principais mudanças corporais identificadas com a maternidade na adolescência em nosso estudo foram os seios, o peso e a barriga. A mais apreciada foi o crescimento da barriga, possivelmente em função do papel da maternidade na sociedade.

A representação social da maternidade ancorase também nos sentimentos positivos e negativos 
expressados pelos discursos:

Por que prá mim era difícil, cuidar da casa, família, trabalhar cuidar de filho e ia saber mais ou menos o que era. Eu já convivi com muitas pessoas que tiveram filho sozinha, tem as dificuldade né. Principalmente pela educação, por que hoje em dia prá você, claro que filho é importante. Mas hoje em dia as dificuldades são grandes, prá você criar um filho sozinha, prá mim num foi fácil né (E.5).

A maternidade vem incorporada por sentimento de responsabilidade que deve ter com o filho. $\mathrm{O}$ dever de mãe fica definido através de um cuidado adequado para o filho, de educação moral e cognitiva, de amparo emocional e afetivo e qualidade de vida. As dificuldades enfrentadas no desenvolvimento da função de mãe foram representadas num domínio social e cognitivo.

Eu fiquei pensando, como é que eu vou cuidar né desse menino sem eu saber né pegar no menino, nem nada, mas só que a minha mãe foi me ensinando, pronto eu peguei e me acostumei já com a idéia de ficar com ele direto mais eu, pronto foi isso. A dificuldade tem até hoje ainda, nem só nos primeiros. Assim, dos alimentos prá ele, dos primeiros a gente já não tinha o que pudesse dá uma vida que uma criança precisa mais, do mesmo jeito é esses agora. Mesma coisa. A maior dificuldade que eu tenho é aquelas, dos alimentos deles, a gente ter uma casa própria prá gente morar, sem pagar aluguel, tudo isso aí (E.7).

A necessidade de proporcionar uma vida digna para o filho traz à tona as dificuldades adquiridas pela baixa escolaridade das jovens, devido ao abandono da escola. A baixa escolaridade dificulta a educação futura da criança já que as dificuldades passam a ser financeiras também.

O grupo pesquisado de adolescentes refere, com isso, a falta de oportunidade de conseguir um emprego com boa remuneração e falta de tempo para trabalhar já que desempenham o papel de mãe em tempo integral e sozinha. Assim, a dificuldade em sustentar a criança dentro de condições favoráveis de vida torna-se um desafio para a jovem mãe, que deve abdicar de todos os seus prazeres para tentar suprir as necessidades de seus filhos.

Os discursos mostram também a falta de experiência em desempenhar o papel de mãe. As

verbalizações referem-se às dificuldades em amamentar, em identificar doenças, motivo de choros e insegurança no processo de cuidar da criança.

É preciso compreender que os assuntos relacionados à transição ao papel materno não podem ser associados apenas às questões biológicas, mas também às questões sociais, emocionais e psicológicas, pois a complexidade do fenômeno da transição não envolve apenas a mulher, mas toda sua rede de relacionamentos. Para minimizar as dificuldades que a maternidade traz, se faz necessário que a mulher construa suportes alicerçados em conhecimento, responsabilidade, criatividade, segurança, amor, carinho, compreensão e sincronismo, para o seu ajustamento à maternidade ${ }^{(19)}$.

Podemos visualizar na figura 2 as representações sociais das puérperas adolescentes sobre a maternidade e as significações desveladas em suas falas.

Sentidos

Mãe na adolescência

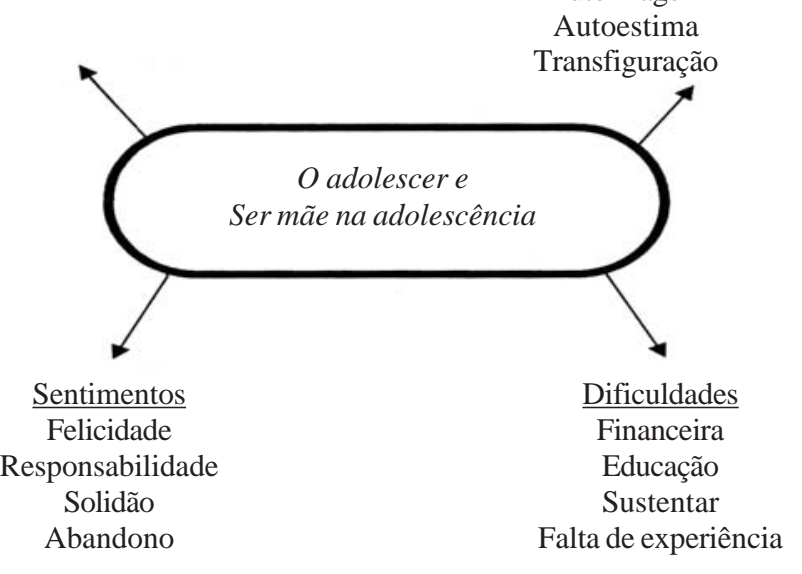

Figura 2 - Representações sociais das puérperas adolescentes mediante a condição de ser mãe. Fortaleza-CE, 2007

\section{CONSIDERAÇÕES FINAIS}

A construção das representações sociais sobre a maternidade na adolescência revela a edificação de opiniões contraditórias. A jovem objetiva as experiências do processo de adolescer repleta de sentimentos positivos. Assim como não considera a gravidez algo ruim, a não ser quando aparece no momento inesperado que é na adolescência.

As contradições mais visíveis são: ser mãe e ser mãe na adolescência em que a primeira passa a ser concebida como uma virtude, enquanto a segunda estereotipada como prisão através das dificuldades enfrentadas no desenvolvimento do papel e pela perda de liberdade. A representação da maternidade na adolescência deve ser compreendida dentro de um 
conjunto de seus aspectos sócio-afetivos e psicossociais. A prática de uma orientação mais abrangente durante a gestação só será possível a partir da valorização da interação entre o universo vivenciado pela mãe adolescente e a adequada percepção sobre as mudanças que ocorrem na sociedade.

Contudo, o contexto da maternidade na adolescência revela a importância de programas educativos sobre a saúde sexual, com enfoque na intersetorialidade entre as escolas, os serviços de saúde e a sociedade para desenvolver mecanismos que identifiquem e intervenham junto as adolescentes com alto risco para a maternidade precoce.

\section{REFERÊNCIAS}

1. Governo do Estado do Ceará. Capacitação em saúde do adolescente para PSF: caderno da programação organização do atendimento terceira etapa. Escola de Saúde Pública do Ceará; 2005.

2. Ministério da Saúde (BR). Gravidez na adolescência. [acesso em 2004 Mai 24] Disponível: http:// portal.saúde.gov.br/saúde/área.c/m?id_área=241.html.

3. Ministério da Saúde (BR). Pré-natal e puerpério: atenção qualificada e humanizada - manual técnico. Brasília: Ministério da Saúde, Secretaria de Atenção à Saúde, Departamento de Ações Programáticas Estratégicas, 2005.

4. Frida SA, Andrade-Silva M. Crenças, informações e comportamentos sexuais na "Era AIDS": um perfil dos adolescentes da Ilha de Paquetá, RJ, Brasil. Rev Mestrado em Sexologia. 1999;5 (2):61-84.

5. Ballone GJ. Gravidez na adolescência [2003]. [acesso em 2004 Mai 03]. Disponível: http://sites.uol.com.br/ gballone/infantil/adolesc3.html

6. Bee H. A criança em desenvolvimento. Porto Alegre: Artmed; 2003.

7. Sant'Anna MJ, Coates V. Gravidez na adolescência: visão da hebiatria. In: Coates V, Beznos VW, Françoso LA, organizadores. Medicina do adolescente. São Paulo: Sarvier; 2003. p.361-71.

8. Governo do Estado do Ceará. Plano de atenção à saúde dos adolescentes e jovens do estado do Ceará. Fortaleza; 2001.

9. Moscovici S. A representação social da psicanálise. Rio de Janeiro: Zahar; 1978.

10. Jodelet D. As representações sociais. Rio de Janeiro: UERJ; 2001.
11. Bardin L. Análise de Conteúdo. Lisboa: Edições 70; 1977.

12. Rodrigues MSP, Leopardi MT. O método de análise de conteúdo: uma versão para enfermeiros. Fortaleza-CE: Fundação Cearense de Pesquisa e Cultura; 1999.

13. Albuquerque AX. Representações sociais de adolescentes grávidas face à questão da gravidez na adolescência [dissertação]. João Pessoa (PB): Universidade Federal da Paraíba; 2003.

14. Tsunechiro MA, Bonadio IC. A família na rede de apoio da gestante. Fam Saúde Desenv 1999;1(1/2):103-6.

15. Gama S, Granado N, Szwarcwald CL, Leal MC. Experiência de gravidez na adolescência, fatores associados e resultados perinatais entre puérperas de baixa renda. Cad Saúde Publ. 2002;18(1);153-61.

16. Dias ACG, Gomes WB. Conversas, em família, sobre sexualidade e gravidez na adolescência: percepção das jovens gestantes. Psicologia: Reflexão e Crítica. 2000;13(1):109-25.

17. Figueiredo B. Maternidade na adolescência: Consequências e trajectórias desenvolvimentais. Análise Psicológica 2000;4(18):485-98.

18. Menezes IHCF, Domingues MHMS. Principais mudanças corporais percebidas por gestantes adolescentes assistidas em serviços públicos de saúde de Goiânia. Rev Nutr. 2004;17(2):185-94.

19. Alves MA, Gonçalves CSF, Martins MA, Silva ST, Auwerter CT, Zagonel IPS. A enfermagem e puérperas primigestas: desvendando o processo de transição ao papel materno. Cogitare Enferm. 2007 Out/Dez;12(4):41627. 